\title{
A new therapy (MP29-02*) effectively treats patients with seasonal allergic rhinitis who suffer most from the bothersome nasal symptom of congestion
}

\author{
Claus Bachert ${ }^{*}$, David Price ${ }^{2}$, Glenis Scadding ${ }^{3}$, Wytske Fokkens ${ }^{4}$, Peter Hellings ${ }^{5}$, Ullrich Munzel ${ }^{6}$, Jean Bousquet ${ }^{7}$
}

From 9th Symposium of Experimental Rhinology and Immunology of the Nose (SERIN 2013)

Leuven, Belgium. 21-23 March 2013

\section{Background}

In clinical practice, allergic rhinitis (AR) patients frequently present with a predominant or particularly bothersome symptom, most frequently nasal congestion.

\section{Objective}

To assess the efficacy of MP29-02* (a novel intranasal formulation of azelastine hydrochloride [AZE] and fluticasone propionate $[\mathrm{FP}]$ ) in patients with seasonal AR (SAR) suffering predominantly from nasal congestion, compared to commercially available AZE or FP nasal sprays and placebo.

\section{Methods}

610 patients ( $\geq 12$ years old) with moderate-to-severe SAR were randomized into a double-blind, placebo-controlled, 14-day, parallel-group trial to MP29-02*, AZE or FP nasal sprays and placebo (all given as 1 spray/nostril bid; total daily dose: $548 \mu \mathrm{g}$ AZE, $200 \mu \mathrm{g}$ FP]. Patients were defined as 'nasal congestion predominants' if their maximum symptom score at baseline was the nasal congestion score $(\mathrm{n}=368)$. Both reflective total nasal symptom score ( $r$ TNSS; max score $=24$ ) and nasal congestion symptom score ( $\max$ score $=6$ ) reduction were assessed in these patients to show effect on their overall nasal symptom burden, as well as specific relief from nasal congestion.

\section{Results}

MP29-02* induced the greatest reduction in rTNSS in patients complaining of nasal congestion (-5.64), compared

'Ghent University Hospital, Dept of Oto-rhinolaryngology, Ghent, Belgium Full list of author information is available at the end of the article to -3.93 for FP (Diff $-1.71 ; 95 \%$ CI $-3.00,-0.43 ; \mathrm{p}=0.0093$ ), -3.28 for AZE (Diff -2.36 ; 95\% CI $-3.51,-1.21 ; \mathrm{p}<0.0001$ ) and -2.63 for placebo (Diff -3.01 ; 95\% CI $-4.14,-1.88$; $\mathrm{p}<0.0001$ ), corresponding to a relative treatment difference of $57 \%$ to FP and $79 \%$ to AZE. These nasal congestionpredominant patients treated with MP29-02* also experienced a significantly greater reduction in their nasal congestion score; -1.41 vs -0.90 for FP (Diff: -0.51 ; $95 \%$ CI $-0.83,-0.19 ; \mathrm{p}=0.0018$ ), -0.83 for AZE (Diff: $-0.58 ; 95 \%$ CI $-0.88,-0.29 ; \mathrm{p}=0.0001$ ) and -0.69 for placebo (Diff -0.72 ; $95 \%$ CI $-1.02,-0.42 ; \mathrm{p}<0.0001)$, with a relative treatment difference of $71 \%$ to FP and $81 \%$ to AZE. Neither AZE nor FP significantly differed from placebo in terms of nasal congestion reduction in these patients.

\section{Conclusion}

Unlike currently available first line therapy, MP29-02* effectively reduced nasal congestion and the overall nasal symptom burden of patients suffering predominantly from nasal congestion. This indicates that for nasal congestion predominant patients a decongestant might not be required prior to MP29-02* administration, and further supports the position of MP29-02*as the drug of choice for the treatment of AR.

"Dymista
Author details

Ghent University Hospital, Dept of Oto-rhinolaryngology, Ghent, Belgium. ${ }^{2}$ University of Aberdeen, Dept of General Practice \& Primary Care, Abderdeen, UK. ${ }^{3}$ The Royal National Throat, Nose and Ear Hospital, London, UK. ${ }^{4}$ Academic Medical Center, Dept of Otorhinolaryngology, Amsterdam, the Netherlands. ${ }^{5}$ University Hospitals Leuven, Dept of Otorhinolaryngology, Head and Neck Surgery, Leuven, Belgium. ${ }^{6}$ Meda Pharma, Biostatistics \& 
Published: 16 July 2013

doi:10.1186/2045-7022-3-S2-P39

Cite this article as: Bachert et al:: A new therapy (MP29-02*) effectively treats patients with seasonal allergic rhinitis who suffer most from the bothersome nasal symptom of congestion. Clinical and Translational Allergy 2013 3(Suppl 2):P39.

Submit your next manuscript to BioMed Central and take full advantage of:

- Convenient online submission

- Thorough peer review

- No space constraints or color figure charges

- Immediate publication on acceptance

- Inclusion in PubMed, CAS, Scopus and Google Scholar

- Research which is freely available for redistribution

Submit your manuscript at www.biomedcentral.com/submit
() Biomed Central 